\title{
What does quality healthcare look like to adolescents and young adults? Ask the experts!
}

\author{
Authors: Melinda Edwards, ${ }^{\mathrm{A}}$ Caron Lawson, ${ }^{\mathrm{B}}$ Safiyyah Rahman, ${ }^{\mathrm{C}}$ Kerry Conley, ${ }^{\mathrm{D}}$ Hannah Phillips ${ }^{\mathrm{E}}$ and \\ Rebecca Uings ${ }^{\mathrm{F}}$
}

It is widely recognised that developmentally appropriate services for adolescents and young people improve both healthcare experience and health outcomes. However, there is limited evidence of using young people's expertise to evaluate services, or of young people participating in service developments or design to meet their healthcare needs. This report covers both the process and outcomes of a collaborative project with a group of young people (aged 17-25 years) who are 'experts by experience'. We used qualitative mixed methodology to derive themes from narrative accounts of these young people's healthcare experiences to develop an assessment framework that they identified as being relevant to evaluating services. Informing young people about other assessment measures currently in use (including the Department of Health's You're Welcome quality criteria) enabled the group to further develop their views and refine their proposed assessment framework. This paper is co-authored with young people, enabling them to directly voice their views about healthcare services. Reflections on this process and recommendations for working more collaboratively with young people to evaluate healthcare services are also given.

KEYWORDS: Adolescents, young adults, services, evaluation, involvement

\section{Introduction}

The Department of Health (DH) has documented a clear expectation for patients to be involved in all aspects of their care, including service design, delivery and the evaluation of services. ${ }^{1,2}$ There is good recognition that the unique and valuable insights that patients provide from

Authors: ${ }^{\text {A }}$ consultant clinical psychologist, Evelina London Children's Hospital, Guy's and St Thomas' NHS Foundation Trust, London, UK; ' Bassistant psychologist, Evelina London Children's Hospital, Guy's and St Thomas' NHS Foundation Trust, London, UK; 'Evelina expert patient, Guy's and St Thomas' NHS Foundation Trust, London, UK; ' Evelina expert patient, Guy's and St Thomas' NHS Foundation Trust, London, UK; 'Evelina expert patient, Guy's and St Thomas' NHS Foundation Trust, London, UK; ' Evelina expert patient, Guy's and St Thomas' NHS Foundation Trust, London, UK their direct experiences can inform and improve clinical practice. In this paper, we report on both the process and the outcome of a project with a group of young patients who are experts by experience, to develop a framework for a service-evaluation measure for young people to use. The aim was to move beyond a more familiar method of using young people's views to inform such a process to a more active collaboration with young people, from the design of the project to the co-authorship of this paper, in which their views about evaluating their healthcare are directly communicated.

The DH has set out clear expectations for good practice in young adult and adolescent (YAA) care. ${ }^{3,4}$ However, evidence from the Care Quality Commission report, From the pond into the sea, suggests a shortfall between policy and practice. ${ }^{5}$ The report specifically highlights a need to ensure that care whether based in paediatric, adolescent or adult services - is age-appropriate, and recommends that adolescence and young adulthood is recognised as a distinct developmental phase. However, this population often falls between the gaps of paediatric and adult services, and, because YAAs tend to account for only a small proportion of any one doctor's caseload, this can create challenges in the development of experience, understanding and confidence in managing the wider aspects of their care.

YAAs are already recognised as being a particularly vulnerable group, with poor health outcomes. ${ }^{4,6}$ In addition, YAAs with chronic health conditions are reported as having low levels of educational achievement and social participation. ${ }^{7}$ The developmental goals of this phase, and consequent changing roles and responsibilities are played out against the upheaval of a move to adult health, education and social-care systems, which places new and often greater demands on young people. Evidence also suggests that health behaviours established in adolescence persist into adult life, highlighting the importance of engaging young people in their healthcare throughout this developmental phase ${ }^{8}$ and ensuring that services effectively meet their needs.

The DH's You're Welcome quality criteria are a recognised example of an assessment framework that enables services to evaluate how appropriate they are for young people. ${ }^{9}$ Criteria for You're Welcome were drawn from examples of effective practice in health and mental healthcare settings. Good evidence exists for involving young people in the accreditation 
of services as being 'young people friendly' - ie participation in service visits to assess if services have reached the You're Welcome standards. ${ }^{10}$ However, these criteria were not designed to be used by young people for evaluation of their personal experience of services - they are not written from their perspective and do not use their words or criteria. As such, there is still a lack of evaluation measures that are 'young people friendly' to use.

A growing number of studies demonstrate how young people's participation can inform the development of a patientexperience measures and the design of research to create these measures. ${ }^{11}$ These studies provide a good foundation to engage young people in collaborating fully in both the design of measures and implementation of service improvements. One collaborative assessment measure is the 15 Steps Challenge Toolkit, ${ }^{12}$ which is based on the first 15 steps walked within a particular clinical area. Young people and healthcare staff walk these steps together and their observations form the basis of discussions to create a service-improvement plan. However, because this measure is based on observational impressions, the more complex relational aspects of directly receiving healthcare are not taken into account.

Within Evelina London Children's Hospital, an established adolescent group (Evelina Pride) has gained considerable experience of acting as an expert reference group and consulting with the hospital trust on adolescent and young adult issues. Group members also have direct experience of using the 15 Steps Challenge Toolkits, alongside senior nursing staff as part of an engagement process to improve the inpatient environment. The aim of this project was to engage this expert group of young people and use their lived experience and expertise of monitoring and assessing services to create a process for developing a proposed framework for evaluating services.

\section{Method}

Members of Evelina Pride $(\mathrm{n}=12)$ were involved in the initial design phase and development of the project. According to availability, young people either chose to join a core working group $(n=5)$ or were invited to become part of a wider indirect peer-review group to support the work. The project had four phases - a project-development meeting, two workshops, and authoring of the paper (Box 1). Because of health issues, only four young people (aged 17-25 years) from the core working group participated in the two subsequent workshops and coauthored this paper.

A qualitative mixed methodology was used for this study. Workshops enabled core group members to discuss their experiences and expectations of healthcare, and review DH recommendations for quality healthcare and current measures for evaluating services. An iterative design was used to refine the narrative themes arising from these workshops, enabling the creation of statements about care that the young people felt represented the criteria that they would use to evaluate services and the development of an assessment framework. Key to the whole process was the continuous review of all work by the core group and wider Evelina Pride Review Group, enabling engagement and agreement with the outcomes of this process.

\section{Results}

In line with an active-collaboration approach, a summary of the narrative of the workshop discussions has been agreed and written in the words of the core group of young people. The remainder of this paper is therefore presented from this point of view, as 'we'.

We grouped our collective experiences, depicting what we felt was important in 'my world' under the three areas of me, my life and my healthcare (Fig 1). We particularly wanted to communicate to doctors just how much is going on for us, and the range of things we might be juggling, planning, and thinking about. It is easy for doctors to only see the tip of the iceberg. In reality, it is hard to separate the parts of our world, because it varies depending on how much our health and life issues impact on each other, and how important issues are. Also, like everyone else, we have good days and bad days, which affect how we feel about everything. We are still trying to work out who we are. We may feel confident, independent and 'adult' in some ways, but not in all ways. We are clear, however, that we don't want to be defined by our condition. We don't expect doctors to know everything about our lives, but we would like them to be interested in us as people and to give us a chance to tell them about things that are important to us.

From our discussions of both our experiences and reviews of current service evaluation measures, we agreed on statements that reflected these experiences and our expectations of quality healthcare for young people. The statements informed our final framework (Table 1). We agreed the 'You're Welcome' criteria ${ }^{9}$ and the ' 15 Step Challenge ${ }^{10}$ Toolkit, covered a broad range of areas, so we focussed on both what we saw as the most important criteria and also the 'gap' in these measures when developing our framework. The results which follow are a summary of our discussion about the themes we felt should be part of an assessment framework.

\section{Communication}

Good communication linked with all other themes we identified. It is key to feeling listened to, feeling understood and being able to understand what is said to us. We discussed how our common response to doctors 'getting it wrong' was just 'switching off'. This included when they came across as patronising by talking down to us (we might know quite a bit, but just not be confident to tell them this). We also felt embarrassed when put on the spot (it can feel like being in the classroom and being quizzed), or when we got lost in technical explanations we did not understand, which made us feel stupid. Another main reason for switching off was doctors talking to our parents and not to us, as if we weren't even there. It does not feel easy to say we don't understand, are feeling left out of the conversation, or feel uncomfortable talking about particular things. There are some subjects we may find difficult to raise ourselves, and appreciate when doctors open up these areas, but it is more comfortable when they give us some warning they are going to talk about something personal (fertility, for example) rather than just asking us outright.

Getting our name right helps! We also felt that having some normal conversation at the beginning of the appointment helped to make us feel more relaxed. One of us felt that doctors 


\section{Box 1. Project method.}

\section{Phase 1: Project development at Evelina Pride group meeting $(n=12)$}

Aim: to develop a project plan and agree membership of core working group and wider review group.

Idea and plan for project discussed and agreed.

Evelina Pride members either became part of the core group - which involved attending workshops and co-authoring the paper - or wider review group to participate indirectly.

Initial discussion of young people's expectations of quality healthcare and their experiences highlighted good and poor practice. Three main themes of communication, relationship and understanding of patients as adolescents or young adults emerged.

\section{Phase 2: Workshop 1 (core working group $(n=4)$ )}

Aim: to provide a personal context to enable the development of a framework for service evaluation.

Discussion of young people's experiences of healthcare building on broad themes highlighted by Evelina Pride group meeting.

Key issues noted and mapped into visual model (Fig 1).

Thematic analysis of narrative from workshop discussion.

Model sent via email to wider review group for comments, amendments and agreement.

\section{Phase 3: Workshop 2 (core working group $(n=4)$ )}

Aim: to provide a service context for the core group through a structured discussion about key Department of Health recommendations for quality services and a review of available service evaluation methods.

Summary of Care Quality Commission paper presented to group (see online-only supplementary material: S1).

Structured discussion of using satisfaction measures and the 15 Steps Challenge Toolkit.

Review of You're Welcome quality criteria.

Evaluation of the gap between their experiences and existing criteria for evaluating services.

Identification of themes they felt were integral to an assessment framework.

Key words and phrases from narrative in both workshops used to create statements, which formed the criteria in the assessment framework.

Statements/criteria sent to wider review group via electronic surveys to enable feedback and agreement of criteria to be used in final framework.

\section{Phase 4: Co-authoring final paper (core working group $(n=4)$ )}

Aim: to agree final framework, model and write-up of paper.

Core group led on results section of paper, providing a narrative of their experiences to illustrate criteria selected for assessment framework.

Paper revised and final version agreed following successive drafts with feedback from wider review group through final meetings and emails.

were sometimes uncomfortable about talking to us and so went straight to the point (ie the medical bit) without any conversation, which did not help to give us confidence in them.

Good communication between our doctors is also very important. We have to see so many different professionals that we can end up having to repeat ourselves and our history. Some of us have had pretty awful things happen and it can be difficult for us to have to talk about these things over and over again. It is also difficult to remember everything in our history, so we have had to learn to keep key information accessible, such as on our phones, so it is available.

\section{Relationship and respect}

It was important to all of us that doctors and nurses showed an interest in us and accepted us as people, such as remembering important things about us or by asking about our lives. Also, we needed them to be sensitive to what was going on in our lives, such as not trying to change our medication just before we were about to sit exams at college.
Most of us had known our doctors and nurses in paediatrics for a long time, and felt known, with the social part being important alongside the medical care. We agreed that we needed to get to know our doctor to really trust them and feel able to ask or tell them anything. Without this trust, or a sense that they get you, it is easy to end up just answering their questions and not really opening up. Feeling judged was quite a worry for many of us, as was being told not to do something by our doctor because they would not do it, rather than this being medical advice.

Respect and trust also worked both ways: being able to know and trust our doctor, but also them showing that they could trust us too. One of us reported being allowed to tweak the dosage of their medicines in paediatrics depending on the level of pain, and then being clearly told on first moving to adult services that the consultant had to agree any changes, which felt very undermining.

\section{Privacy and confidentiality}

We all agreed that, irrespective of how kind professionals are towards us, much of what happens in our appointments and care 


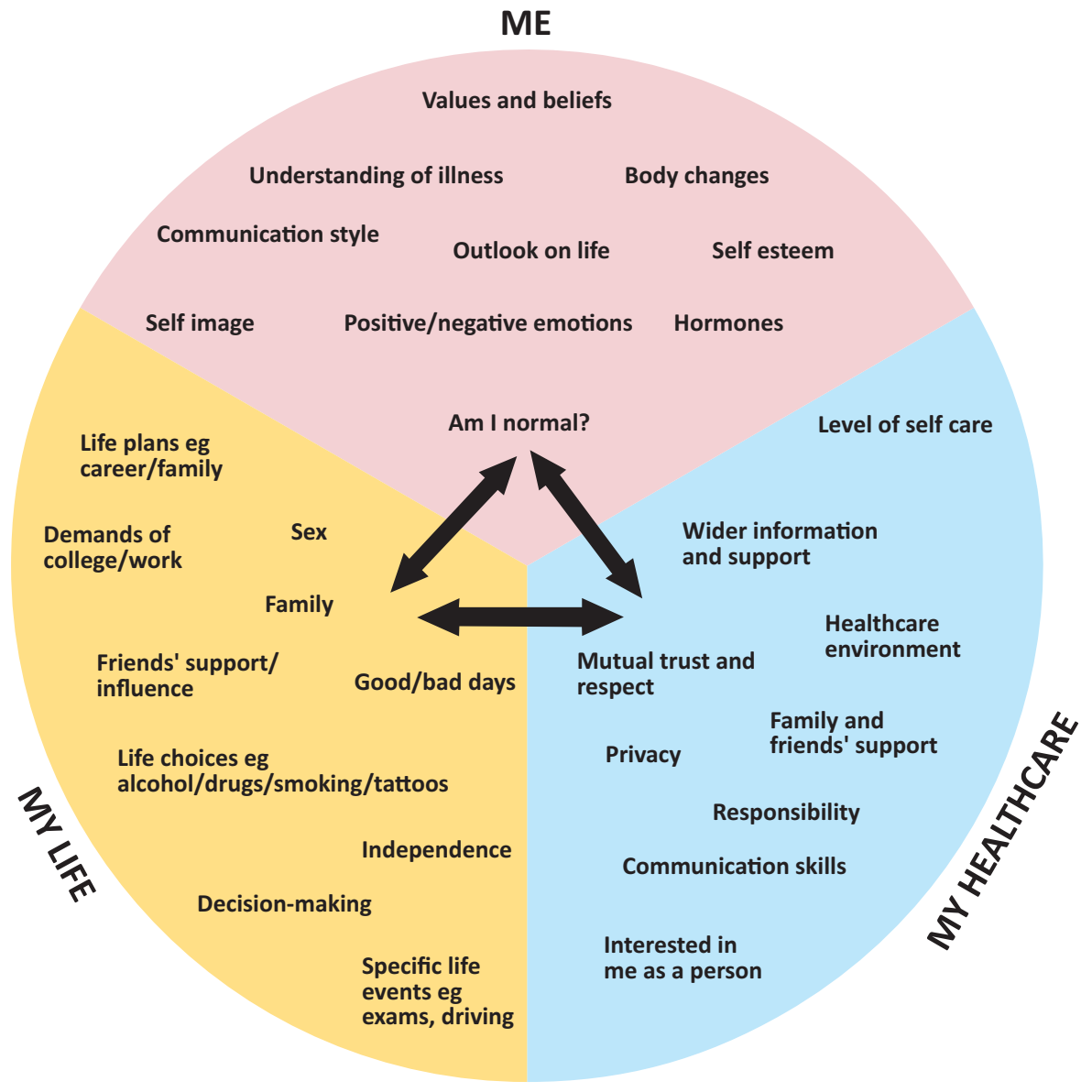

Fig 1. My world.

is embarrassing and uncomfortable because we are particularly self-conscious about our bodies. Sensitivity to our needs for privacy is really important to us. Although confidentiality has never been a problem for any of us, we could see how important this might be for other people, and when our doctors had discussed issues of confidentiality, we really appreciated this.

\section{Environment}

All of us felt that we stood out as being much younger than other patients, particularly on the adult inpatient ward. It's not that there is anything wrong with old people; we just don't have very much in common with them. As young people, we want to feel that we are around positive people and have a sense of getting on with things, but sometimes the setting and older, sick people around us made us feel hopeless. One of us had even recently delayed seeing the doctor to try and avoid being admitted to a ward. The adult inpatient environment needs to have positive and interesting things available to us, and to also take into account the needs of our younger siblings, who get bored very easily during a visit if there is nothing for them to do. We found that ward staff were often too busy to find activities for us and the wards often did not have much available for us.

\section{Family and friends}

Our family and friends are really important to us. Our families have gone through so much with us and really know how to support us. Our friends are 'the family we choose' and help us to feel connected to the real world. It was difficult when one of us was told quite bluntly that a parent could not stay with them on the adult ward. There were particular times, such as when having a procedure, that we really needed our mums around! Some nurses were more friendly than others, but did not spend much time with us, so when our parents left, we really felt on our own.

Our parents always attended our paediatric appointments, but as some of us have got more confident with our doctors, we are attending some adult appointments on our own (even though our parents still ask us about what was said and what our results showed). One of us described that, because her mum continued to drive her to appointments (as she could not manage public transport or hospital transport by herself) she did not feel it was fair to 'kick her out' of the appointment, but welcomed the doctor taking the lead in suggesting that she had some time by herself as well as inviting her mum in for part of the appointment.

\section{Involvement}

Within our group, we felt that we had gained a great deal of knowledge and skills in managing our conditions and would want to be fully involved in all care decisions. We also wanted understanding that, in some ways, we might still be coming to terms with our condition, even though we might have always 
lived with it. Therefore, we could still need support to be involved and take responsibility for our care, and this should be properly discussed and not assumed.

We were all interested in being more involved in helping to develop and improve our services, but had mixed feelings about using questionnaires to do this. We felt we had never previously been informed as to what the questionnaires were for and how they were used, as we never heard anything back after we filled them in (and some of us had filled in plenty of forms). We compared this to the 15 Step Challenge Toolkit, which was a more direct way of giving feedback as we visited with a senior nurse, and had time to discuss our observations with her. It is sometimes easier to put what you want to say into words, particularly more personal things, rather than just ticking boxes or writing things down on forms. We appreciate that some feedback may be needed from larger numbers, so online surveys or questionnaires might have to be used, but at the very least, the questions on the form need to feel relevant to us and our care.

\section{Information and preparation}

There was great variation within our group regarding our access to information, and the preparation we received particularly about moving to adult services. Examples of good practice included one of us attending a very helpful joint health and education workshop as preparation for college. In contrast, another member of our group who did not have access to this reported feeling 'put off' attending university as she was worried about how she would cope with her condition. She felt that her hospital care was quite separate from her education, unlike in paediatric services when the nurse attended her education reviews and informed school about her needs.

Another challenging experience was receiving information that was clearly targeted at a much older population. In the only available hospital booklet about cardiac pacemakers, all photographs were of older people who were at least 60 . The distress and frustration from this prompted one group member to write her own self-help booklet, Wired up - $a$ young person's manual, ${ }^{14}$ so that other young people did not experience this.

We were very supportive of the $\mathrm{DH}$ recommendations for preparation for transition, ${ }^{7,13}$ and would have found these helpful. It was very scary that we did not know our doctor or how to find our way around the adult clinic and ward settings. Even relatively small things, like knowing the adult ward routines and where the kitchen was, would have been helpful. It would also have been good to know about any support services or benefits that were available.

\section{Feeling connected}

We all experienced challenges in feeling connected to young people in a similar situation to us. It was therefore particularly helpful when our healthcare team provided us with opportunities to do this. Some of us had been recommended groups and websites. We found Facebook groups very supportive and good for reassuring us that our feelings and problems were normal. We also valued the opportunity of being able to contact our doctors and nurses in between appointments (both by phone and by email), which gave us both reassurance and support.

\section{Concluding remarks from young people}

We agreed as a group that all these themes covered were important to us, but appreciate that other people may have different issues that are important to them in their services. For example, we have experience in both paediatric and adult services and so can make comparisons between them, which may lead us to having different expectations from someone who had only attended adult health services. We would be interested to continue to work on developing a measure to evaluate services, using our framework, and particularly using opportunities to talk directly with doctors and nurses and jointly evaluate services with them.

Before getting involved in this project, none of us had been aware of any of the research relating to young people and healthcare. We had no idea doctors found us so difficult! We were all surprised that our doctors and wider healthcare team were not specifically trained in caring for our age group, although we did hear about a number of online teaching resources that they could access (www.e-lfh.org.uk/programmes/adolescent-health/, www. mefirst.org.uk and www.unil.ch/euteach/home.html). We felt that understanding the key issues for YAAs, and communicating well with them is central to good care. We also agreed that, as young people, we had the skills and experience to be a key part of this training. This project has given us an opportunity to say things in our language about what quality healthcare looks like to us. We would also be interested in teaching doctors and nurses through joint workshops, role-playing exercises (with us acting out some of our experiences, both good and not so good) and 'ask us' teaching sessions. An important aspect of these sessions would be doctors getting to know us as people, when we are feeling $\mathrm{OK}$ and more like ourselves, rather than just when we are unwell or in a patient role. We feel it is a real responsibility and opportunity to teach doctors about us and what quality of care is really about for us.

\section{Concluding remarks and recommendations from healthcare professionals}

A key aspect of this project is the level of collaboration with young people throughout the whole process, from the design to the shared ownership of the outcome, including co-authoring this paper. To enable their full participation, it was important to ensure that they were working from an informed position, which included providing them with a wider knowledge base of views about healthcare and ways of evaluating services.

It is also important to consider how to give a voice to those young people who wish to be involved but who are unable to participate directly. In this project, we aimed to promote inclusivity by inviting the wider Evelina Pride group to review and offer their input via online surveys and emails. Social media offers even more creative opportunities to involve young people to be involved in developing these project ideas further.

We hope that both the process and proposed framework will be a helpful resource for other services to take forward with their own young people's forums, to enable an extension of criteria and development of a more comprehensive assessment framework, which could be particularly relevant to other specific settings and clinical populations. The measure needs to be relevant and shaped by the young people who are going to be using it. 


\begin{tabular}{|c|c|}
\hline Theme & Example of outcome criteria \\
\hline \multirow[t]{3}{*}{ Communication } & The doctors and other members of the team listened to me and talked to me in a way I could understand \\
\hline & I felt able to raise and ask any questions I had \\
\hline & There was good communication between all members of the healthcare team about me and my care \\
\hline \multirow{5}{*}{$\begin{array}{l}\text { Relationship } \\
\text { (trust and } \\
\text { respect) }\end{array}$} & My doctor and healthcare team were aware of, and sensitive to, other things going on in my life \\
\hline & I felt the doctor and healthcare team respected my views and decisions \\
\hline & I felt that important information was remembered about me from one appointment to the next \\
\hline & I felt accepted as a person by the doctors and healthcare team \\
\hline & I had confidence in the expertise and skills of my healthcare team \\
\hline \multirow{2}{*}{$\begin{array}{l}\text { Privacy and } \\
\text { confidentiality }\end{array}$} & I was given enough privacy in my care and treatment \\
\hline & I was given information about confidentiality and told about what information would be shared \\
\hline \multirow[t]{3}{*}{ Environment } & The setting I was treated in was comfortable and supported me in being as independent as I could be \\
\hline & The healthcare team were all friendly and kind to me \\
\hline & There were enough resources for people my age (eg internet access) \\
\hline \multirow{2}{*}{$\begin{array}{l}\text { Family and } \\
\text { friends }\end{array}$} & My family and friends were made to feel welcome and their role in supporting me was respected \\
\hline & I was given the option for friends and family to be there when I wanted them there (eg during appointments, on the ward) \\
\hline \multirow[t]{2}{*}{ Involvement } & I felt supported to take a comfortable level of responsibility for my care and decisions about my care \\
\hline & I was given an opportunity to be involved in giving feedback and/or suggesting ideas to improve services \\
\hline \multirow{3}{*}{$\begin{array}{l}\text { Information } \\
\text { and preparation }\end{array}$} & I was given information about how the adult services run and what to expect \\
\hline & I was given useful information about other services (eg benefits, support services) \\
\hline & The information I was given was accessible, useful and easy to understand \\
\hline \multirow[t]{2}{*}{$\begin{array}{l}\text { Feeling } \\
\text { connected }\end{array}$} & $\begin{array}{l}\text { There were opportunities to link in with other people my age who are going through the same things (eg groups or } \\
\text { websites such as Facebook) }\end{array}$ \\
\hline & I was able to contact my nurse or doctor between appointments if I neede \\
\hline
\end{tabular}

Collaborating with young people on this project was an extremely rewarding process. We learned from them how they would like more opportunities to more directly share their views with healthcare staff, and work jointly to develop measures and evaluate services.

\section{Acknowledgements}

We would like to thank the Evelina Pride group and the paediatric psychology team at Evelina London for their helpful comments and suggestions. We would also like to thank Ros Little, Hannah Ward and Emma Hull for their contributions to this paper.

\section{References}

1 Keogh B. Review into the quality of care and treatment provided by 14 hospital trusts in England: overview report. London: NHS England, 2013.

2 Berwick D. A promise to learn - a commitment to act: improving the safety of patients in England. London: Department of Health, 2013.

3 Kennedy I. Getting it right for children and young people: Overcoming cultural barriers in the NHS so as to meet their needs. London: Department of Health, 2010.

4 Children and Young People's Health Outcomes Forum. Children and young people's health outcomes strategy. London: Department of Health, 2012.

5 Care Quality Commission. From the pond into the sea: Children's transition to adult health services. London: Care Quality Commission, 2014.
6 Children and Young People's Health Outcomes Forum. Report of the Children and Young People's Health Outcomes Forum 2014/15. London: Department of Health, 2015.

7 Colver A, Longwell S. New understanding of adolescent brain development: relevance to transitional healthcare for young people with long term conditions. Arch Dis Child 2013;98:902-7.

8 Viner R, Barker M. Young people's health: the need for action. BMJ 2005;330:901-3.

9 Department of Health. You're Welcome quality criteria: making health services for young people friendly. London: Department of Health, 2011.

10 Cheetham M. Involving young people in health service delivery. Nursing Standard 2013;27:35-40.

11 Girling I, Day E, Fazakerley K et al. What young people want from their diabetes team: developing a patient reported experience measure (PREM) for young people with type 1 diabetes. Practical Diabetes 2015;32:142-7a.

12 The Fifteen Steps Challenge - quality from a patient's perspective, 2013. Available online at www.rcn.org.uk/_data/assets/ pdf_file/0004/466078/01_The_15_Steps_Challenge_toolkit.pdf [Accessed 25 March 2015].

13 Department of Health. Transition: Moving on well. London: Department of Health, 2008.

14 Wired up - a young person's guide to having a pacemaker. Available online at www.evelinalondon.nhs.uk [Accessed 1 March 2016].

Address for correspondence: Dr M Edwards, Paediatric Psychology department, Sky Level 6, Evelina London Children's Hospital, Westminster Bridge Road, London SE1 7EH, UK.

Email: melinda.edwards@gstt.nhs.uk 